\title{
Periodical Binding Schedules for Improved Reader Service in University and College Libraries
}

Mrs. Hughes is assistant librarian, Birmingham-Southern College.

$\mathrm{T}$ HE TREND within recent years toward greater use of serial literature as a major tool in higher education is clearly reflected in college and university library acquisitions. It is freely acknowledged, however, that the necessity of removing this type of material from circulation for binding, during which interval serials are not available to the reader, creates a serious service problem. It is also acknowledged that such interruptions in service ought to be minimized but that no real effort toward that end has been made. Since the importance of the service problem increases proportionately with the greater dependence upon serial literature, there is an increasing need to discover ways of making periodical literature constantly accessible.

Recognition of the problem is not new. Several administrators have given it consideration, one of whom concluded that a bindery on the campus would provide the solution. ${ }^{1}$ Later he devised an altogether different approach, ignoring the location of the bindery entirely. ${ }^{2}$ More recently the report of a survey on the use and preservation of periodicals touched briefly on inaccessibility during the binding period and offered several proposals for improved

1 Ayer, Thomas P. "The Value of a University Bindery." Library Journal 38:518-519, Sept. 1913.

2 Ayer, Thomas P.; "A Schedule for Binding and Rebinding Magazines." Library Journal 62:856-857, Nov. 15,1937 . serials service. ${ }^{3}$ Since neither these nor other reports were intended as comprehensive studies of the problem, the writer recently undertook an investigation which was presented to the School of Library Service, Columbia University as an essay for the master's degree.

Information bearing specifically upon interruption of reader service during the binding period was gathered from sixtythree college and university libraries. The inquiry was conducted by means of questionnaires submitted to the libraries of all institutions offering the graduate program leading to the doctorate. This selection rested upon the comparable quality and diversity of service programs, since graduate students, undergraduates and faculty use these libraries. The questionnaire covered the principal aspects of the problem in four sections: (1) Measures used or proposed for use in scheduling binding; (2) Opinions concerning the effect of proposed measures on interruptions in serials service; (3) Organization of periodical and binding departments; and (4) The location of the bindery. Attention was centered upon practices governing the flow of volumes into the bindery. The point of view was that of the assistant servicing serials material. To set up objective criteria for evaluating data from the responding libraries, expert opinion was solicited from nine librarians, specialists in reference,

${ }^{3}$ Casford, E. Lenore, "Periodicals, Their Use and
Preservation," Wilson Bulletin, $13: 593-596$, May r 939. 
periodicals and binding, through the medium of the same questionnaire.

The investigation showed that the majority of libraries follow some plan in sending periodicals to the bindery, but few plans systematically consider reader service. Most plans are based solely on preservation of materials. Of the 63 libraries returning information, only four had conducted a formal survey of unfilled requests which tested the binding program. Seven other libraries claimed to have made informal analyses of reader service. For purposes of analysis, libraries were grouped according to their acknowledged plan in scheduling binding: ( $\mathrm{I}$ ) those having no plan; (2) those having a plan based on reader service; and (3) those whose plan most nearly met the standards set up by the experts. This latter group was identified as those libraries practicing any four of seven scheduling measures involving attention to individual periodical titles recommended by the experts, as contrasted with the recommended general measures. It was concluded, after an examination of data, that the adoption of certain measures for planning and controlling binding schedules could minimize interruptions in service to readers.

\section{Measures Used or Proposed for Use in Scheduling Binding}

Sixteen possible procedures, based on reader consideration, were first submitted to experts whose opinions of the relative desirability of each measure were to serve as criteria for evaluation of current practices and opinions. On the basis of a point system adopted for translating these opinions into numerical values, ten of the measures, marked with asterisks in the following list, were endorsed by the experts as constituting a binding plan based on reader service.

\section{General measures}

$*_{1}$. Prearrangement with bindery as to timing of shipments

*2. Understanding with bindery as to time limit allowable for binding

3. Binding done only during school vacation periods

$*_{4}$. Volumes available for a considered interval after receipt of title page and index

\section{Measures involving consideration of specific} titles

*5. Calendar for binding weeklies, monthlies and quarterlies at specified intervals

6. Duplication of all periodical titles, with staggered binding

*7. Duplication of part of titles, with staggered binding for those duplicated

*8. Staggered schedule for abstracts and the periodicals abstracted

*9. Division of important indexed or abstracted titles in subject fields with staggered binding

*Io. Division of important indexed titles in general field with staggered binding

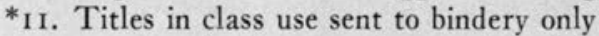
upon notice from professor that they are no longer required for current class work

12. List of titles ready for bindery submitted to heads of instructional departments for release before sending to bindery

*13. Staggered schedule for similar titles with other libraries on campus

14. Staggered schedule for similar titles with libraries in same community

15. Staggered schedule for similar titles with other libraries in district

16. Bound duplicates purchased on cooperative basis making freer duplication possible because of lowered cost

The above list of measures was considered to be the core of the investigation. All libraries were asked in the questionnaire, first, whether they followed any of the suggested procedures and second, whether any or all of those listed would be essential or desirable components of a plan aimed at 
uninterrupted reader service. None of the responding libraries used or suggested for use measures not endorsed by the experts. Of the ten measures the experts had recommended one, "a staggered schedule for abstracts and the periodicals abstracted," was rejected by the libraries.

Among all the libraries three measures commonly constitute the binding plan: "Prearrangement with bindery as to timing shipments," "A time limit for returning work" and "A staggered schedule for duplicated titles" in the collection so that one copy is always available. Only the latter measure involves consideration of individual periodical titles. Those libraries acknowledging no organized plan use but one general measure, "Understanding with bindery as to time limit allowable for binding." However, those groups of libraries whose plans are based on reader service use two or more general measures and from one to five of the measures necessitating consideration of individual titles. The one procedure not in use by any member of these groups was "the staggered schedule for titles duplicated in other campus libraries."

Responses from all the libraries as to whether any or all of the measures submitted would be essential or desirable components of a proposed plan aimed at uninterrupted reader service illustrated the difference between practice and opinion. Although a majority of the libraries answering the questionnaire employ only three of the listed measures, in their proposed plan they recommend in addition a "staggered schedule for periodicals in the general field." Those libraries with no organized plan also find this measure desirable and endorse it together with the general measure for "prearrangement of shipments to bindery." The group claiming a plan based on reader service uses the three general measures and also "staggers the binding schedule for any serials received in duplicate." In proposing a superior service plan, they recommend three additional specific measures: "A staggered schedule within subjeet fields," "A staggered schedule within the general field" and "Cooperation with other campus libraries by staggering identically held titles." The general measure of keeping volumes available for any interval after they are complete with title page and index would be eliminated. The libraries most nearly meeting the standards of the experts endorse the same number of measures for their proposed plan as they now use, but prefer like the previous group to make a substitution by adopting the cooperative scheme involving other campus libraries. Each group, after deliberating on the suggested means for improving current periodical service, has therefore recognized some deficiency in present planning and has added some number of measures or pointed out the need for more detailed consideration of individual periodical titles for the achievement of a binding plan giving the reader maximum service.

Opinions Concerning the Effect of Proposed Measures on Interruptions in Serial Service

The experts and the responding libraries also designated the probable effect on reader service of the binding plan each proposed. Five degrees of effectiveness were suggested ranging from "uninterrupted service" to "continually interrupted service." No attempt was made to have the individual libraries evaluate the effectiveness of the plan already in use. Responses indicated that in no group was there a majority which believed its proposed plan could achieve uninterrupted service, although three individual libraries supported the possibility. However, all groups thought the second highest rating. "infrequently interrupted service," could result if their particular type 
of plan was adopted. While it is not possible that all types of schedules could produce identical results, opinions unanimously support the likelihood of an improvement in reader service upon the adoption of a controlled periodical binding schedule.

\section{Organization of Periodical and Binding Departments}

The possible influence of the many administrative factors on service interruption due to binding practices was also investigated. In the organization of periodical service, according to replies contained in the questionnaire, 70 per cent of the reporting libraries issue such material through a combination of a periodical room and subject reading rooms, or a reference room and subject reading rooms. Libraries having a separate serials department or one merged with documents account for the other 30 per cent. The same relative proportions obtain among libraries in the group which has no organized binding plan and in those whose plans are based on reader service: 70 per cent have subject division and 30 per cent form division. Replies therefore indicate no correlation between the administrative unit and the binding plan.

Increased circulation of current journals outside the library building also appears to have no definite connection with the type of binding schedule followed. Thirty to 46 per cent of all groups allow undergraduates to borrow serials for home use. A majority of all groups grant the faculty, graduate students and other libraries the same privilege.

Separate binding departments were maintained by 28 per cent of the libraries, combined with order department by 34 per cent and combined with periodical department by 38 per cent. About two-thirds of the libraries thus had binding departments attached to service units, those in direct contact with reader demand. These conditions are descriptive of practices among the three selected groups in about the same proportions, establishing an absence of any correlation between binding department organization and type of binding schedule followed.

Regarding the administrative unit delegated with responsibility for binding preparation, returns also show marked similarity in present practices among the several groups of libraries. The periodical department handled this function in 44 to 54 percent of cases; the binding department was assigned the responsibility in from to to 36 per cent of libraries and occasionally the chief librarian's office or the order department assumed the duty. The administrative unit responsible for the function, therefore, did not reflect any influence of reader demand on the program adopted.

As to personnel, however, responses indicate a definite connection between administration and the binding schedule adopted. In the great majority of libraries, where planning is at a minimum, the binding supervisor was attached to a technical unit, devoting full time to the preparation of serials for binding, usually having only one assistant. But among those libraries most nearly meeting the standards set up by expert opinion only 8 per cent of the supervisors were attached to technical units, 53 per cent being connected with service units. They did not, therefore, devote full time to binding. In addition they had three or more assistants who handled routine binding details leaving them more free for planning and coordination of the binding program with reader service.

\section{Location of the Bindery}

Libraries were asked in the questionnaire whether they used a bindery located on the campus, an off-campus bindery or a com-

(Continued on page 23I) 
reports can be furnished in terms of definite control factors: (I) Specific reports (2) Series or categories of reports (3) Contract source (4) Sponsoring agency (5) Classification (6) Physical areas or degrees of security clearance.

Requirements for safe storage of classified documents may be found described in detail in the Executive Order on Minimum Standards, referred to above, and need not be considered here. Cataloging, filing and arrangement of classified reports ordinarily present no unique security problems and likewise are not discussed in this paper.

The maintenance of adequate records and control procedures on security-classified reports is an operational problem of the greatest importance. Lax security handling involving compromise of classified information can have serious consequences. Good security can be maintained by means of simple, effective procedures, plus constant vigilance. The basic control record is a permanent accession record identifying and showing the ultimate disposition of all classified reports received and distributed. It is essential this record give evidence of internal completeness. In addition to the accession or "log" record, a 2-3-4-copy receipt is used to show transfer of accountability when a classified report changes hands. Receipts are usually optional for the "restricted" and "confidential" classifications, but are mandatory for "secret" and "top secret." For internal circulation, some classified report libraries use the standard $3^{\prime \prime} \times 5^{\prime \prime}$ library book card to record the temporary holder of the document. At some time or other most classified report libraries are required to take an inventory or to make a spot check of their holdings in order to determine whether any reports are missing, to assess security deficiencies, and also to evaluate the adequacy of their record controls.

For the sake of brevity and simplicity it has been necessary in several instances to make statements which for complete accuracy would require much greater qualification and elaboration than there is time to give them. In addition, there are many problems deserving more attention and fuller treatment. The need to reconcile maximum dissemination with adequate security control has required the development of many new procedures and the application of library principles and techniques to new and highly specialized material.

\section{Periodical Binding Schedules (Continued from page 226)}

bination of both. Eighty-three per cent of libraries reporting either had no campus bindery available or could not have all binding done on the campus. Those libraries following binding schedules based on reader service, as well as those with no organized plan had access to campus facilities in the same proportion as the total reporting. Analysis indicated that the location of the bindery is not a factor in the formulation of binding schedules based on reader demand. Also in the opinion of the majority of libraries reporting, the location of the bindery could not of itself contribute to the effectiveness of a schedule aimed at improved reader service.

\section{Conclusion}

This paper suggests specific procedures for developing serials binding schedules to minimize disruption in service to readers. Ideally such scheduling should be controlled by those who have first-hand knowledge of reader demand. Adoption of these or other specific techniques can be expected to improve reader service generally. 